\title{
Natural egg mass deposition by the Humboldt squid (Dosidicus gigas) in the Gulf of California and characteristics of hatchlings and paralarvae - ERRATUM
}

DANNA J. STAAF, SUSANA CAMARILLO-COOP, STEVEN H.D. HADDOCK, AL C. NYACK, JOHN PAYNE, CESAR A. SALINAS-ZAVALA, BRAD A. SEIBEL, LLOYD TRUEBLOOD, CHAD WIDMER AND WILLIAM F. GILLY

doi:10.1017/Soo25315408001422 Published by Cambridge University Press, June 2008.

The volume of the wild egg mass was incorrectly calculated as 3130 . This error appears on pages 762 and 767 of the article. The correct volume is $6280 \mathrm{l}$. Using this correct volume, the potential number of eggs in the entire mass ranges from 1.2 to 4 million (not 0.6 to 2 million as stated on pages 762 and 765 ).

The authors apologize for this error.

REFERENCE

Danna J. Staaf, Susana Camarillo-Coop, Steven H.D. Haddock, Al C. Nyack, John Payne, Cesar A. Salinas-Zavala, Brad A. Seibel, Lloyd Trueblood, Chad Widmer and William F. Gilly (2008). Natural egg mass deposition by the Humboldt squid (Dosidicus gigas) in the Gulf of California and characteristics of hatchlings and paralarvae. Journal of the Marine Biological Association of the UK, 88, pp 759-770. doi:10.1017/ Soo25315408001422. 